\title{
The Heart Sodium Channel Phenotype for Inactivation and Lidocaine Block
}

\author{
Jonathan C. MAKIELSKI, MD
}

\section{SUMMARY}

The heart $\mathrm{Na}$ channel, although resembling other voltage-gated $\mathrm{Na}$ channels, has important functional and structural differences. For heart channels expressed in oocytes, the midpoint of the inactivation relationship was 13 $\mathrm{mV}$ negative to that of rat skeletal muscle $\mathrm{Na}$ channels, and sensitivity to tonic lidocaine block was approximately 5 times more sensitive for heart. Co-expression with the $\beta$ subunit increased the difference in inactivation midpoint to 24 $\mathrm{mV}$, largely by changing the midpoint of the rat skeletal muscle channel by 10 $\mathrm{mV}$ in the positive direction. Co-expression with $\beta 1$ decreased lidocaine sensitivity for heart but not for skeletal muscle $\mathrm{Na}$ channels, and decreased but did not eliminate the greater heart sensitivity to lidocaine block. The differences in inactivation are likely to account for some, but not all, of the differences in lidocaine sensitivity. This cardiac phenotype is important for the role the channel plays in cardiac physiology and pathophysiology, and also may lead to elucidation of structure-function relationships (Jpn Heart 1996; 37: 733-739)

Key words: Cardiac Local anesthetic Ion channels Na current Kinetics Recombinant DNA Tonic block Structure-function

T IDOCAINE, administered systemically, acts as an antiarrhythmic drug. When it is administered locally in higher concentrations, lidocaine acts as a local anesthetic. Both of these actions are caused by block of $\mathrm{Na}$ channels and lidocaine is often used as a typical representative of both local anesthetics and antiarrhythmic drugs. Although neurotoxicity occurs with lidocaine when it is used to treat arrhythmias, this side effect is concentration dependent and occurs at higher concentrations (for review see 1). What explains the therapeutic ratio? Is the cardiac Na channel intrinsically more sensitive to lidocaine?

Lidocaine exhibits the property of use-dependent block, that is, extra block accumulates with repetitive depolarizations as a result of higher affinity binding to the inactivated state. ${ }^{2)}$ The relative sensitivity of lidocaine for $\mathrm{Na}$ channels in heart may result from an intrinsic difference in lidocaine affinity for the different $\mathrm{Na}^{+}$channel isoforms, but also could result from increased binding to the inacti-

From the Department of Medicine, Section of Cardiology, University of Wisconsin, Madison, WI, USA.

Supported by National Institutes of Health PO1 HL20592 and HL56441, the University of Wisconsin Cardiovascular Research Center, and the Oscar Rennebohm Foundation.

Address for correspondence: Jonathan C. Makielski, MD, University of Wisconsin Clinics and Hospitals, 600 Highland Ave H6/349, Madison, WI 53792, USA. 
vated state in heart during the longer action potential without any differences in affinity. In the first comprehensive voltage clamp study of lidocaine block on cardiac Na current, Bean and colleagues ${ }^{3)}$ compared their results with studies published previously for non-heart channels. They concluded that lidocaine showed similar interactions with the channel itself and attributed at least most of the difference to greater block in heart tissue during the greater dwell time in the inactivated state. One of the difficulties of using previously published data for comparison of heart with non-heart lidocaine binding, however, is that lidocaine block is sensitive to experimental conditions including divalent ions, monovalent ions, $\mathrm{pH}$, temperature, and the specific voltage protocols used to elicit the block. The experiments must be done, as much as possible, under identical experimental conditions.

A preliminary report using native cells under nearly identical conditions ${ }^{4)}$ suggested that the cardiac channel in rat ventricle had an intrinsically higher affinity for lidocaine than did the brain channel in cultured neuroblastoma cells. More recently, cloned cardiac channels expressed in oocytes ${ }^{5,6)}$ have also suggested an intrinsically higher affinity for the cardiac isoform. This report reviews the previous literature and provides further data to support this contention. In addition, because inactivation is also critical for lidocaine binding, the isoform specific differences in steady-state inactivation are also reviewed.

\section{Methods}

The human heart Na channel $\alpha$-subunit (hH1) was kindly provided by Drs. H. Hartmann (Baylor University, Houston, TX) and A.M. Brown (Ramelkamp Research Center, Cleveland, $\mathrm{OH}$ ), the rat skeletal muscle Na channel $\alpha$-subunit $(\mathrm{r} \mu \mathrm{l})$ by Gail Mandel (SUNY Stonybrook, NY), and the Na channel $\beta 1$ subunit by John W. Kyle (University of Chicago, Chicago, IL). The methods for preparation of cRNA, Xenopus oocytes, and two microelectrode voltage clamps are standard and have been previously published." Briefly, Xenopus oocytes were injected with 50-150 ng of cRNA for the $\alpha$-subunit $(\mathrm{hHl}$ or $\mathrm{r} \mu \mathrm{l})$ alone, or in some cases a mixture of cRNA for the $\alpha$ and cRNA for the $\beta 1$ subunits in 3-9 fold excess of that for the $\alpha$ subunit (total 50-150 ng). One to seven days after injection $I_{\mathrm{Na}_{\mathrm{a}}}$ was recorded from cRNA-injected oocytes with a two electrode voltage bath clamp. A Dagan CA-1 (bath clamp) with a series resistance compensation circuit (TEV-208, Dagan) was used to make recordings. All recordings were made at $20-22^{\circ} \mathrm{C}$ in a flowing bath solution consisting of (in $\mathrm{mM}$ ): $90 \mathrm{NaCl}, 2.5$ $\mathrm{KCl}, 1 \mathrm{CaCl}_{2}, 1 \mathrm{MgCl}_{2}$, and $5 \mathrm{Hepes,} \mathrm{pH}$ 7.2. Lidocaine in appropriate amounts was added from a $100 \mathrm{mM}$ stock solution in distilled water. Electrodes contained $3 \mathrm{M} \mathrm{KCl}$ and had resistances that ranged from 0.2 to $1.5 \mathrm{M} \Omega$. Data were ac- 
quired using pClamp6 software (Axon Instruments) onto an Intel-486 based computer. Data were digitized at a $42 \mathrm{kHz}$ and were low pass filtered at $10 \mathrm{kHz}$ ($3 \mathrm{~dB})$.

Data were fit to model equations using non-linear regression (Procedure NLIN) using SAS (Cary, NG) statistical software running on a SUN ELC workstation. Parameter estimates are given \pm the standard error for the parameter estimate. Steady-state inactivation relationships were fit to Fractional $\mathrm{I}_{\mathrm{Na}_{\mathrm{a}}}=\mathrm{I}_{\mathrm{Na} \text {-max }}$ $\left[1+\exp \left(V_{c}-V_{1 / 2}\right) / k\right]^{-1}$ where $I_{\text {Na-max }}$ is the predicted maximum peak $I_{N a}, V_{1 / 2}$ and $\mathrm{k}$ are fitted parameters representing the mid-point and slope respectively of the Boltzmann relationship. Tonic lidocaine block data were fit to a single site binding relationship as Fractional $I_{\mathrm{Na}_{a}}=1 /\left(1+\right.$ [idocaine] $\left./ \mathrm{K}_{\mathrm{d}}\right)$ where $\mathrm{K}_{\mathrm{d}}$ is the dissociation constant (assuming block as an index of binding) and is equivalent to the half blocking dose. Mean data are reported with their standard deviation. All determinations of statistical significance of mean data were performed by using a student $\mathrm{t}$-test for comparisons of two means.

\section{Results}

For cloned $\alpha$-subunit isoforms expressed in oocytes and studied under identical conditions (sce example in Figure 1), the midpoint of the steady-state inactivation relationship was significantly more negative in heart by $17 \mathrm{mV}$ in the example and by $13 \mathrm{mV}$ on average (Table). Coexpression with the $\beta 1$ subunit increased this difference to $24 \mathrm{mV}$ (Table) because the $\beta 1$ subunit had a greater effect to shift the relationship in the positive direction for the skeletal muscle channel than for the heart channel. Brain channels $(\mathrm{rB} 2 \mathrm{a}+\beta$ in the Table) studied under identical conditions ${ }^{5}$ had the same midpoint as skeletal muscle channels $(r \mu 1+\beta$ in the Table $)$ suggesting that this relatively negative midpoint is a characteristic phenotype of the cardiac $\mathrm{Na}$ channel. These results with co-expression of $\beta 1$ are consistent with those of Nuss $\mathrm{et}^{1{ }^{6 /}}$ summarized in the Table. They are also consistent with results obtained in native rat ventricular myocytes compared with brain channels in neuroblastoma cells ${ }^{4)}$ and summarized in the Table. These data taken together strongly suggest that this negative midpoint, although modified by the $\beta 1$ subunit, is an essential feature of the cardiac isoform of the $\alpha$ subunit.

Lidocaine block of $\mathbf{I}_{\mathrm{Na}}$ can be classified as phasic and non-phasic block. Non-phasic block, also callcd rest block, is block occurring either in the absence of prior depolarizations (first pulse block) or at very low pulsing frequencies (tonic block). First pulse block, defined as the relative decrease in $I_{N a}$ for the first depolarization in lidocaine compared with the current measured without lidocaine, was used as a measure of non-phasic or tonic block. The holding potential was 


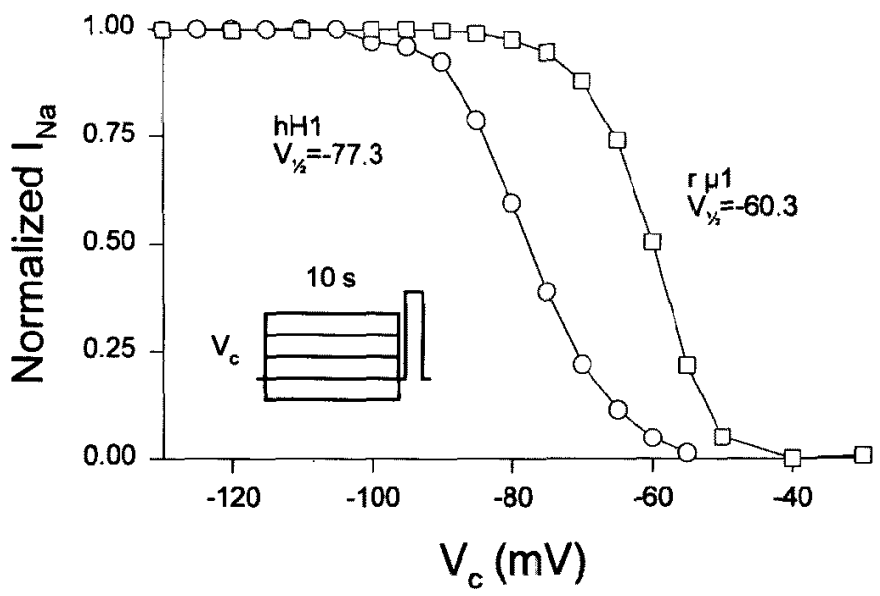

Figure 1. The steady-state inactivation relationship for the heart $\mathrm{Na}$ channel is more negative than that for skeletal muscle. Steady-state availability for inactivation was assessed by a standard "ho-type" protocol (see protocol inset). Previous results suggested a 10 s conditioning duration was required to reach "steady-state"." The figure shows a typical example from an oocyte injected with $\mathrm{hH} l(\mathrm{O})$ and a second oocyte with $\mathrm{r} \mu \mathrm{l}$ ( $\square$ ). Data were normalized to the peak current present at $-120 \mathrm{mV}$ and plotted against the conditioning potential $V_{c}$. Midpoints of fits to a Boltzmann relationship (see methods) are shown on the figure, and summary data are given in Table.

Table. Tonic Lidocaine Block for Cardiac and Non-cardiac Channels

\begin{tabular}{|c|c|c|c|c|c|c|c|c|c|}
\hline $\begin{array}{c}\text { Heart } \\
\text { isoform }\end{array}$ & $\mathrm{Kd} \mathrm{mM}(n)$ & $\mathrm{V}_{1 / 2}(\mathrm{mV})$ & $\begin{array}{l}\text { Non- } \\
\text { heart }\end{array}$ & $\underset{(\mathrm{n})}{\mathrm{K}_{\mathrm{d}} \mathrm{mM}}$ & $\mathrm{V}_{\mathrm{J} / 2}(\mathrm{mV})$ & $\underset{(\mathrm{mV})}{\mathbf{H P}}$ & $\begin{array}{l}\text { Sens. } \\
\text { ratio }\end{array}$ & $\begin{array}{l}V_{1 / 2} \\
\text { diff }\end{array}$ & Ref \\
\hline $\begin{array}{l}\text { hHl } \\
\text { (Oocytes) }\end{array}$ & $\begin{array}{r}0.41 \pm .06 \\
(21)\end{array}$ & $-78 \pm 3$ & $\mathrm{r} \mu \mathrm{l}$ & $\begin{array}{r}2.00 \pm 3.7 \\
(10)\end{array}$ & $-61 \pm 4$ & -120 & 4.9 & 13 & Present study \\
\hline $\begin{array}{l}\mathrm{hH} 1+\beta \\
\text { (Oocytes) }\end{array}$ & $\begin{array}{r}0.86 \pm .15 \\
(16)\end{array}$ & $-75 \pm 5$ & $r \mu 1+\beta$ & $\begin{array}{r}1.72 \pm .23 \\
(14)\end{array}$ & $-51 \pm 3$ & -120 & 2.0 & 24 & Present study \\
\hline $\begin{array}{l}\text { rhl } \\
\text { (Oocytes) }\end{array}$ & $\begin{array}{r}0.43 \pm 0.5 \\
(37)\end{array}$ & & $\mathrm{rB} 2 \mathrm{a}+\boldsymbol{\beta}$ & $\begin{array}{r}2.11 \pm .28 \\
(7)\end{array}$ & $-52 \pm 2$ & -120 & 4.0 & & $\begin{array}{l}\text { Satin et al } \\
1994\end{array}$ \\
\hline $\begin{array}{l}{ }_{\mathrm{hH}} \mathrm{Hl}+\beta \\
\text { (Oocytes) }\end{array}$ & $\begin{array}{r}.40 \pm .04 \\
(22)\end{array}$ & $-80 \pm 1$ & $r \mu l+\beta$ & $\begin{array}{r}1.17 \pm .03 \\
(19)\end{array}$ & $-60 \pm 1$ & -100 & 2.9 & 20 & $\begin{array}{l}\text { Nuss et al } \\
1995\end{array}$ \\
\hline $\begin{array}{l}\text { rat vent. } \\
\text { (native) }\end{array}$ & $\begin{array}{r}1.80 \pm .22 \\
(16)\end{array}$ & $-87 \pm 6$ & $\begin{array}{l}\text { Mouse } \\
\mathrm{Nb} 2 \mathrm{a}\end{array}$ & $\begin{array}{r}4.20 \pm .16 \\
(14)\end{array}$ & $-78 \pm 8$ & -150 & 2.3 & 9 & $\begin{array}{l}\text { Makielski et } \\
\text { al } 1994\end{array}$ \\
\hline
\end{tabular}

Isoforms of $\alpha$-subunit of the Na channel are: $\mathrm{hH} 1$ human heart Na channel, $\mathrm{rH} 1$ rat heart $\mathrm{Na}$ channel, $\mathrm{r} \mu \mathrm{l}$ rat skeletal muscle, $\mathrm{rB2}$ a rat brain $2 \mathrm{a},+\beta$ indicates co-expression with the $\beta 1$ subunit of the $\mathrm{Na}$ channel, all cloned channel studies done in oocytes. For native channels acutely isolated cells from rat heart ventricle were compared to cultured mouse neuroblastoma cells ( $\mathrm{Nb2a}$ ). $\mathrm{K}_{\mathrm{d}}$ is the dissociation constant (half block) for lidocaine from a fit to a single site binding relationship \pm the standard error for the parameter estimate for the $(n)$ individual experiments at different lidocaine concentrations. $V_{1 / 2}$ is the midpoint of the steady state inactivation relationship (see Figure 1). The sensitivity ratio for lidocaine was calculated by dividing the $K_{d}$ in non heart by the $K_{d}$ in heart. $V_{1 / 2}$ diff is the difference in inactivation midpoints. All differences in $K_{d}$ and $V_{1 / 2}$ between heart and non-heart isoforms are significant by paired t-test at $p<.05$. 


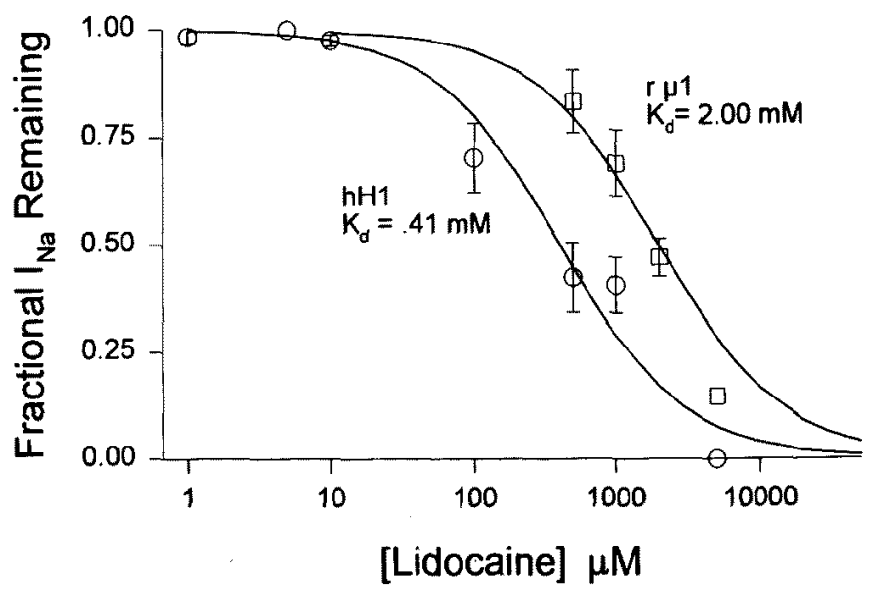

Figure 2. The heart channel is more sensitive to lidocaine than the skeletal muscle $\mathrm{Na}$ channel. Fractional $I_{\mathrm{Na}}$ was measured by taking the peak current for the first dcpolarization from $-120 \mathrm{mV}$ to $-10 \mathrm{mV}$ after exposure to lidocaine and dividing by the peak current present for the same step in control solutions. Data points for $\mathrm{hHl}$ (O) and $\mathrm{r} \mu \mathrm{I}(\square)$ represent means and the bars represent standard deviations for between 2 and 5 experiments ( 21 total for $\mathrm{hH} 1,10$ total for $\mathrm{r} \mu 1$ ). The solid lines represent fits to a single-site binding curve (see methods) with the dissociation constant $\mathrm{K}_{d}$ 's as shown on the figure.

$-120 \mathrm{mV}$ and the test potential was $10 \mathrm{mV}$. Figure 2 shows the dose-response relationships for tonic lidocaine block of $\mathrm{hH} 1$ and $\mathrm{r} \mu \mathrm{l}$ expressed without the $\beta 1$ subunit. The heart channel was approximately five times more sensitive (see sensitivity ratio column in the Table). Co-expression of the $\beta 1$ subunit decreased this difference but did not eliminate it ( $\mathrm{hH} 1+\beta$ and $r \mu 1+\beta$ in the Table). This result is similar to the result of Nuss et $\mathrm{al}^{6)}$ also summarized in the Table. The decreased difference with $\beta 1$ is caused by a reduced decreased lidocaine sensitivity for $\mathrm{hH} 1$ (Table and 7), but $\beta 1$ does not have a significant effect on lidocaine sensitivity for $r \mu 1$. Brain channels ( $\mathrm{rB} 2 \mathrm{a}+\boldsymbol{\beta}$ in the Table) studied under identical conditions (5) had the same $K_{d}$ as skeletal muscle channels $(r \mu l+\beta$ in the Table) suggesting that the greater tonic block sensitivity is a characteristic phenotype of cardiac channels. A greater sensitivity was also found for $\mathrm{Na}$ channels in native rat ventricular myocytes compared with brain channels in neuroblastoma cells ${ }^{4)}$ and is summarized in the Table. These data taken together strongly suggest that the greater sensitivity is an essential feature of the cardiac isoform of the $\alpha$ subunit itself and not a result of different study conditions. 


\section{Discussion}

The properties of the voltage gated $\mathrm{I}_{\mathrm{Na}}$ from different tissues bear a remarkable similarity to each other ${ }^{8}{ }^{8}$ Heart, skeletal muscle, and nervous tissue $I_{N a}$, however, differ in their sensitivity to toxins such as tetrodotoxin, sea anemone toxins, and to divalent cations such as $\mathrm{Cd}^{2+}$ (see 9 for review), and subtle kinetic differences have been described. The characterization of various properties of $\mathrm{I}_{\mathrm{Na}}$ depends greatly upon the experimental conditions under which they are measured including: ionic conditions, $\mathrm{pH}$, temperature, technical quality of the voltage clamp, voltage clamp techniques (ie, patch clamp mode, cell preparation), and the particular voltage clamp protocols used to elicit the properties. For these and other reasons, detecting and describing differences such as gating kinetics and sensitivity to local anesthetics is difficult when comparing various reports in the literature.

More than a dozen isoforms of the $\alpha$-subunit of voltage-dependent $\mathrm{Na}$ channel have been cloned and many of these have been expressed and studied by voltage clamp (see 10 for review). Although similar in structure and overall function, expression and study of different isoforms under identical conditions and with identical protocols have elicited and characterized important specific functional differences. Differences in kinetics and lidocaine sensitivity had been suspected by comparison of results from diverse studies in heart and non-heart preparations under various experimental conditions. The present study reviews previous studies and offers new data to show that under identical study conditions the typical cardiac phenotype for steady-state inactivation is more negative than brain and skeletal muscle $\mathrm{Na}$ channels, and that the cardiac phenotype for tonic block by lidocaine is one of greater sensitivity.

An important consideration in measuring tonic block is the holding potential. Lidocaine has higher affinity for the inactivated state, and as the membrane holding potential becomes more depolarized, then tonic block increasingly reflects binding to the inactivated state and becomes greater. This likely explains the greater sensitivities observed by Nuss et $\mathrm{al}^{(6)}$ who measured tonic block at $-100 \mathrm{mV}$ compared with our results at $-120 \mathrm{mV}$ (Table), and also explains the lower affinities observed at $-150 \mathrm{mV}$ in native cells. ${ }^{4}$ Could the greater sensitivity of heart channels to tonic block be simply a reflection of the more negative inactivation kinetics? This certainly accounts for some of the difference and would also be of physiological and pathophysiological significance. That the difference persists (although diminished somewhat) at the more negative holding potentials of $-120 \mathrm{mV}$ and $-150 \mathrm{mV}$ (Table) suggests that an intrinsic difference in affinity beyond inactivation kinetics may exist.

Isoform spccific sensitivitics to the tetrodotoxin and saxitoxin have been 
exploited to define the structures responsible for tonic toxin block ${ }^{11)}$ and phasic toxin block ${ }^{12)}$ by site mutagenesis. Mutagenesis work on the $\mathrm{Na}$ channel has suggested residues on domain $4 \mathrm{~S} 6$ as forming a putative local anesthetic binding site, ${ }^{13)}$ but the possible contributions of the other domains are not known. Recent work with $\mathrm{Na}$ channels made chimeric between heart and skeletal muscle channels has suggested that isoform differences in block must be attributed to all four domains. ${ }^{14)}$ Thus, in addition to helping explain the therapeutic effectiveness and therapeutic ratio of lidocaine for the antiarrhythmic effect, the cardiac phenotype for inactivation and lidocaine block will likely lead to characterization of the structure-function relationship for these important $\mathrm{Na}$ channel functions.

\section{ACKNOWLEDGEMENTS}

The author expresses gratitude to Mr. Jim Limberis for performing the oocyte clamp experiments, to Dr. Jack Kyle for his molecular expertise, to Dr. Zheng Fan for his technical assistance, and to Drs. Harry Fozzard and Craig January for their assistance and support.

\section{REFERENCES}

1. Makielski JC, Arnsdorf MF. The Pharmacology of Lidocaine, In: Dangman KH, Miura DS, editors. Electrophysiology and Pharmacology of the Heart. New York: Marcel Dekker Inc., 1991, 561.

2. Hondeghem LM, Katzung BG. Time- and voltage- dependent interaction of antiarrhythmic drugs with cardiac sodium channels. Biochim Biophys Actá 1977; $472: 37398$.

3. Bean BP, Cohen CJ, Tsien RW. Lidocaine block of cardiac sodium channels. J Gen Physiol 1983; 81: $613-42$.

4. Makielski JC, Fan $Z$. Phasic block of cardiac and nerve Na channels by lidocaine under uniform conditions. Biophys J 1993; 64: A89.

5. Satin JS, Kyle JW, Rogart RB, et al. Lidocaine block of heart and brain Na channel isoforms. J Gen Physiol 1994; 104: 18a.

6. Nuss HB, Tomaselli GF, Marban E. Cardiac sodium channels $(\mathrm{hHl})$ are intrinsically more sensitive to block by lidocaine than are skeletal muscle (Mu1) channels. J Gen Physiol 1995; 106: 1193-209.

7. Makielski JC, Limberis JT, Chang SY, et al. Coexpression of beta-1 with cardiac sodium channel alpha subunits in oocytes decreases lidocaine block. Molec Pharmacol 1996; 49: 30-9.

8. Hille B, editor Ionic Channels of Excitable Membranes, 2nd ed. Sunderland, MA: Sinauer Associates, 1992.

9. Fozzard HA, Hanck DA. Structure and function of voltage-dependent sodium channels: A comparison of brain II and cardiac isoforms. Physiol Rev 1996; In press.

10. Goldin AL. Voltage-gated sodium channels, In: North RA, editor. CRC Handbook of Receptors and Channels, vol II. Ligand- and voltage-gated ion channels. Boca Raton, FL: CRC Press, 1994, 73.

11. Satin J, Kyle JW, Chen M, et al. A mutant of TTX-resistant cardiac sodium channels with TTXsensitive properties. Science 1992; 256: 1202-5.

12. Satin JC, Kyle JW, Rogart RB, et al. Post-repolarization block of cloned sodium channels by saxitoxin; the contribution of pore-region amino acids. Biophys J 1994; 66: 1353-63.

13. Ragsdale DS, McPhee JC, Scheuer T, et al. Molecular determinants of state-dependent block of $\mathrm{Na}+$ channels by local anesthetics. Science 1994; 265: 1724-8.

14. Makielski JC, Limberis J, Chen L-Q, et al. Inactivation and lidocaine block phenotypes in wild type and chimeric (heart and skeletal muscle) Na channels. Biophys J 1996; 70: A132. 